\title{
WATER DISTRIBUTION ASSESSMENT APPLIED TO MATHEMATICAL MODEL OF CONTINUOUS CASTING OF STEEL*
}

Charles Sóstenes Assunção ${ }^{1}$ Roberto Parreiras Tavares ${ }^{2}$ Guilherme Dias Oliveira ${ }^{3}$

\begin{abstract}
A mathematical model of heat transfer and solidification for a continuous casting of round billets was developed. The water flux density of the secondary cooling zone was experimentally measured, using an apparatus in industrial scale with two types of nozzles, flat jet and full cone jet. The profiles of water distribution were applied on the mathematical model. The results showed that the water distribution is not uniform in both longitudinal and angular directions owing to the unevenness of the spray and to the curvature effect of the round billet. This non-uniformity causes important variation of the heat transfer coefficients and superficial temperature of the billet, especially in the first cooling zones, where the temperature is higher. The mathematical model was used to simulate a change of nozzle type in the first cooling zone. The results showed that the heat flux and superficial temperature variations were reduced with a full cone jet nozzle in comparison with the flat jet nozzles.
\end{abstract}

Keywords: Water flux distribution; Heat transfer coefficient; Secondary cooling; Mathematical model.

1 Mechanical engineer, Dr., Engineer, Energy and Utilities Department, Vallourec Tubos do Brasil, Belo Horizonte, Minas Gerais, Brazil.

2 Associate Professor, PhD, Metallurgy and Materials Department, Universidade Federal de Minas Gerais, Belo Horizonte, Minas Gerais, Brazil.

3 Metallurgist engineer, Undergraduate Student, Metallurgy and Materials Department, Universidade Federal de Minas Gerais, Belo Horizonte, Minas Gerais, Brazil. 


\section{INTRODUCTION}

The quality of the steel in the continuous casting is directed related to the temperature variation during the solidification process [1]. Inappropriate temperature profiles can cause defects such as cracks, deep oscillation marks, depressions, inclusions and geometric deviation [2]. The knowledge of the thermal behavior of the steel is mandatory to define the best operational practices and, consequently, to reduce quality issues. Probably, the most common method to analyze the heat transfer phenomena during the continuous casting of steel is the mathematical modeling. The first mathematical models of heat transfer and solidification of steel in the continuous casting were developed by Mizikar [3] and Lait [4]. Since then, several other mathematical models have been developed. In the mold, the superficial heat flux of the steel can be calculated relating the residence time inside the mold and the average heat flux [5-7]. An alternative approach that has been largely applied [8] is to use the inverse problem of heat conduction through the mold wall. In the secondary cooling zone, the superficial heat flux of steel involves different mechanisms, such as radiation in the dry zones, conduction in the roll contacts and convection due to the water sprays [9]. The heat extraction in the spray zone depends on the water pressure, stand-off distance between the strand and the nozzle, nozzle type, strand surface temperature and water flux. Exhaustive studies have been developed to identify the effect of these parameters of spray on the heat flux $[10,11]$. Most of these studies have been performed in laboratory where a hot steel plate is cooled using commercial nozzles. All the studies agree that, in the temperature range of interest, the water flux has the largest effect on the heat transfer coefficient. Since the water flux density varies locally along the secondary cooling zone, the heat flux and heat transfer coefficient vary locally as well. However, several authors assume a uniform water flux distribution in the same cooling zone in the heat transfer modeling. This assumption can lead to imprecision, especially in the evaluation of local phenomena. Some authors have measured the water flux density of different types of nozzles $[12,13]$ for slabs and square billets and the common conclusion is that the water flux distribution is not uniform. Despite this conclusion, the results of the non-uniformity have not been largely used in the heat transfer modeling [14-16]. Besides that, no reference of water flux density for round billets has been found in literature. The present work regards to a continuous casting machine of round billets that has been facing to some quality problems, such as subsurface and midradial cracks and internal overlapping in the following tube mill process. These defects have been attributed to the non-uniformity of the heat transfer of the billet in the secondary cooling. Therefore, the objectives of the present work are to determine experimentally the water flux density distribution of flat jet and full cone jet nozzles along the secondary cooling zone, to develop a mathematical model of heat transfer and solidification of steel and to investigate the effect of the non-uniformity of the water distribution on heat transfer coefficients (HTC), billet temperatures and shell thickness.

\section{MATERIALS AND METHODS}

The present work was developed considering a continuous casting machine of round billets. This machine has four strands and is capable of producing billets of $180 \mathrm{~mm}$ and $230 \mathrm{~mm}$ of diameters. The primary cooling of the steel takes place in the mold and the secondary cooling takes place in the spray chamber, which has four control 
zones $(0, A, B$ and $C)$. Zone 0 has two spray rings with eight nozzles each and another spray ring with four nozzles. These nozzles have a flat jet profile. In zones $A$, $B$ and $C$, each spray ring has four nozzles at $90^{\circ}$ from one another. These nozzles have a full cone jet profile. After the spray chamber, the round billet is straightened and cut in different lengths.

\subsection{Mathematical model}

The mathematical model of heat transfer and solidification of the billet has been developed taking into account the heat transfer by conduction in both radial and angular direction. The main assumptions are listed below:

- Symmetry of transversal section, only one eighth of the transversal section was modeled;

- The heat transfer by conduction in the casting direction was neglected due to the high Peclet number;

- The latent heat of steel solidification was converted into an equivalent specific heat capacity in the mushy zone;

- The density of the steel was considered constant whereas the heat capacity, thermal conductivity and emissivity were temperature-dependent;

- The effects of strand shrinkage were neglected;

- The convective heat flow in the liquid pool and mushy zone was accounted for the effective thermal conductivity ${ }^{9}$.

The strand was divided into several slices of steel that move downwards in the casting direction at the casting speed. The domain of the model was divided in 400 control volumes where the energy balance was applied on, with 40 divisions in the radial direction and 10 divisions in the angular direction. The time interval of calculation $(\Delta \mathrm{t})$ was $0.01 \mathrm{~s}$.

The energy balance was obtained from the general energy conservation equation for cylindrical coordinates. In order to obtain the numerical solution, the Equation 1 was discretized and explicitly solved by finite volume method [17].

$$
\rho \frac{\partial\left(C_{p}^{e q} T\right)}{\partial t}=\frac{1}{r} \frac{\partial}{\partial r}\left(r k_{e f} \frac{\partial T}{\partial r}\right)+\frac{1}{r} \frac{\partial}{\partial \theta}\left(\frac{k_{e f}}{r} \frac{\partial T}{\partial \theta}\right)+S
$$

where $\rho$ is the density of steel $\left[\mathrm{kg} \cdot \mathrm{m}^{-3}\right] ; C_{p}^{e q}$ is the equivalent heat capacity of steel $\left[\mathrm{J} . \mathrm{kg}^{-1} \cdot \mathrm{K}^{-1}\right] ; r$ is the radial position of the control volume $[\mathrm{m}] ; k_{e f}$ is the effective thermal conductivity of steel $\left[\mathrm{W} . \mathrm{m}^{-1} \cdot \mathrm{K}^{-1}\right] ; T$ is the temperature of steel $[\mathrm{K}] ; t$ is time $[\mathrm{s}] ; S$ is the source term used to consider the boundary conditions [W. $\left.\mathrm{m}^{-3}\right]$.

The solidification was considered under equilibrium conditions and the liquid fraction of the steel was determined by means of the lever rule equation [18].

$$
\begin{aligned}
& f_{l}=\frac{\left(T_{0}-T_{L}\right)-k\left(T_{0}-T\right)}{(1-k)\left(T_{0}-T\right)} \\
& k=\frac{C_{l i q}}{C_{\text {sol }}}=\frac{T_{0}-T_{L}}{T_{0}-T_{S}}
\end{aligned}
$$

where $T_{0}$ is the melting temperature of pure iron $[\mathrm{K}] T_{L}$ is the liquidus temperature of the steel [K], $T$ is the temperature of steel [K] $k$ is the partition coefficient.

The equivalent heat capacity of steel in mushy zone was calculated considering the effect of latent heat of steel solidification. 


$$
\begin{aligned}
& C_{p}^{e q}=C_{p}+L_{f} \frac{d f_{l}}{d T} \\
& \frac{d f_{l}}{d T}=\frac{\left(T_{0}-T_{L}\right)}{(1-k)\left(T_{0}-T\right)}
\end{aligned}
$$

Where $C_{p}$ is heat capacity of solid steel $\left[\mathrm{J}^{\mathrm{kg}}{ }^{-1} \cdot \mathrm{K}^{-1}\right] ; L_{f}$ is the latent heat of steel

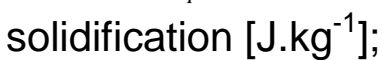

The convective effects in the liquid portion of steel were considered using an effective thermal conductivity.

$$
k_{e f}=k\left[1+(1-C) f_{l}^{2}\right]
$$

where $f_{l}$ is the liquid fraction of steel in the mushy zone; $C$ is a constant equal to 6 ; $k$ is the thermal conductivity of the solid steel.

\subsubsection{Boundary Conditions}

The initial condition is $T_{\text {steel }}=T_{\text {tundish, }}$ i.e., the temperature of steel is the same as that measured in the tundish. In the mold, the boundary condition was expressed in terms of an average heat flux [19] [MW. $\left.\mathrm{m}^{-2}\right]$, as shown by Equation 7.

$$
q_{\text {mold }}=\alpha\left(2,679-0,221 \sqrt{t_{\text {mold }}}\right)
$$

where $t_{\text {mold }}$ is the residence time of each slice of steel inside de mold and $\alpha$ is the calibration factor for each cooling zone.

In the secondary cooling, the heat flux $\left[\mathrm{W} . \mathrm{m}^{-2}\right]$ was calculated by the following equations [20].

$$
\begin{aligned}
& q_{\text {spray }}=h_{g}\left(T_{\text {steel }}-T_{\text {water }}\right) \\
& h_{g}=h_{\text {conv }}+\sigma \varepsilon\left(T_{\text {aço }}+T_{\infty}\right)\left(T_{\text {aço }}^{2}+T_{\infty}^{2}\right) \\
& h_{\text {conv }}=\alpha\left(708 W^{0,75} T_{\text {aço }}^{-1,2}+0,116\right)
\end{aligned}
$$

where $h_{g}$ is the global HTC $\left[\mathrm{W} \cdot \mathrm{m}^{-2} \cdot \mathrm{K}^{-1}\right], T_{\text {steel }}$ is the superficial temperature of steel $[\mathrm{K}], T_{\text {water }}$ is the temperature of the water spray $[\mathrm{K}], h_{\text {conv }}$ is the convection HTC [W.m ${ }^{-}$ $\left.{ }^{2} . \mathrm{K}^{-1}\right], T_{\infty}$ is the environment temperature $[\mathrm{K}], W$ is the water flux density $\left[1 . \mathrm{s}^{-1} \mathrm{~m}^{-2}\right]$. The superficial temperature of the billet was measured by two-color pyrometers (Raytek Marathon MR) at the exit of each cooling zone in the spray chamber, i.e., at the distances from the meniscus $z=1,30 \mathrm{~m}, \mathrm{z}=4,07 \mathrm{~m}, \mathrm{z}=7,65 \mathrm{~m}$ and $\mathrm{z}=11,5 \mathrm{~m}$. The calibration of the model was performed varying the calibration factor $\alpha$, from Equations 7 and 10, to match the calculated superficial temperatures with the values measured at each position. In order to circumvent the effects of the scale, where the temperature is lower than at the surface of the steel, the temperatures considered for validating the model were the peak values of a period of 10 seconds at each position.

\subsubsection{Physical properties of the steel}

The physical properties of the steel considered in the model are shown in Table 1. 
Table 1. Physical properties

\begin{tabular}{|c|c|}
\hline Parameter & Value \\
\hline Density [21] [kg.m $\left.{ }^{-3}\right]$ & 7020 \\
\hline Latent heat of solidification [21] $\left[{\left.\mathrm{J} . \mathrm{kg}^{-1}\right]}^{-1}\right.$ & 272000 \\
\hline Solidus temperature [22] [K] & $1809-415,5 \% C+12,3 \% S i+6,8 \% M n+124,5 \% P+183,9 \% S+4,1 \% A l$ \\
\hline Liquidus temperature [22] [K] & $1809-78 \% C+7,6 \% S i+4,9 \% M n+34,4 \% P+38 \% S+3,6 \% A l$ \\
\hline Specific heat [23] [J.kg $\left.{ }^{-1}\right]$ & $C_{P}=481,482+0,1997 \cdot T_{\text {steel }}$, where $T_{\text {steel }}\left[{ }^{\circ} \mathrm{C}\right]$ \\
\hline Thermal conductivity [24] $\left[\mathrm{W} \cdot \mathrm{m}^{-1} \mathrm{~K}^{-1}\right]$ & $k_{\text {sol }}=15,9106+0,1151 T_{\text {steel }}$ where $T_{\text {steel }}\left[{ }^{\circ} \mathrm{C}\right]$ \\
\hline Emissivity [25] & $\varepsilon=0,0002 T_{\text {secl }}+0,6274$ where $T_{\text {steel }}\left[{ }^{\circ} \mathrm{C}\right]$ \\
\hline
\end{tabular}

\subsection{Experimental Procedures}

The experimental procedures described in this section were performed to obtain the water flux density distribution at several positions along the secondary cooling zones. Figure 2 shows the experimental apparatus that was used to measure the water flux density distribution in the zones $0, \mathrm{~A}, \mathrm{~B}$ and $\mathrm{C}$. The apparatus had the same size and curvature of an actual strand. The spray rings were connected to a flexible hose connected to the system that supplied water to the nozzles. The nozzles used in the experiments were of the same type of those used in the actual plant. The system that supplied water to the nozzles consisted of a centrifugal pump of $0,75 \mathrm{~kW}$, a control valve and a flow meter. A small steel tube of outer diameter of $230 \mathrm{~mm}$ with a hole of one inch of diameter in the wall was positioned at several locations in the impingement area of the water spray. In order to collect the impinging water, a hose was connected to the hole and conducted the water to a graduated vessel, as shown in Figure 1.
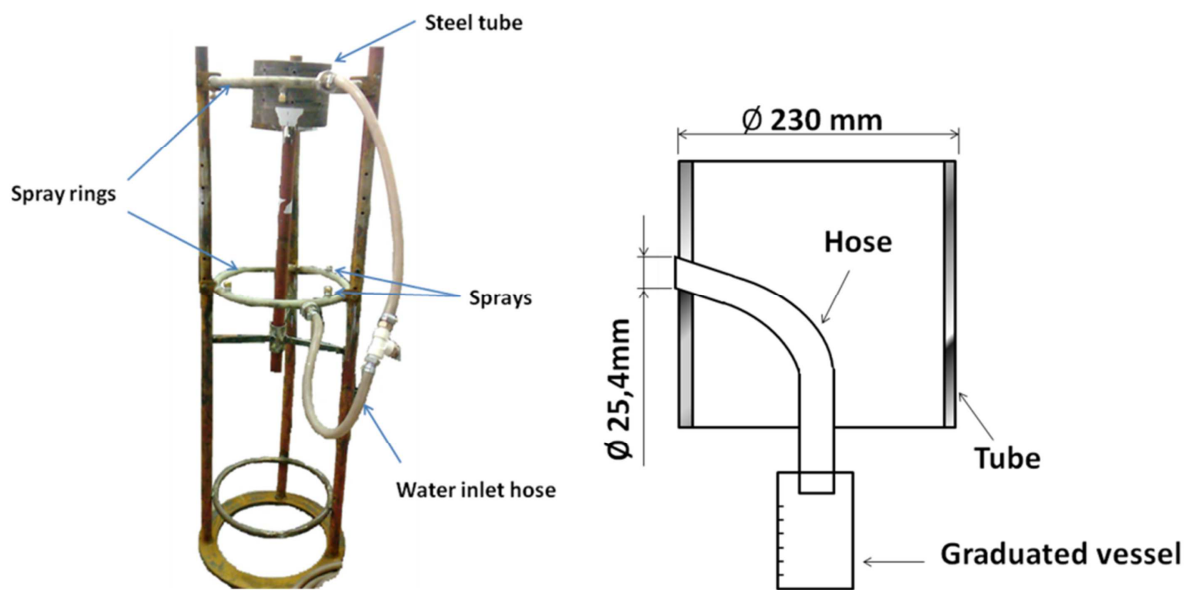

Figure 1. Experimental apparatus for water distribution measurement

In the experiments corresponding to zone 0, nozzles $1 / 4 \mathrm{U}-5010$ (Spraying Systems) were used. The tube was centered in the spray ring in the same way the billet is in the plant. The distance between the collecting hole and the nozzles was $45 \mathrm{~mm}$. The tube was placed at three different angular positions, as shown in Figure 3. At two positions, the hole was aligned with the nozzles and at the other position, the hole was aligned with the intersection of the jet of two nozzles. In the longitudinal direction, the tube was kept at the same position because the water impingement area of the flat nozzles is very thin, as shown in Figure 2. The experiments were 
performed considering both kinds of spray rings, with eight nozzles and with four nozzles. In order to use a lower amount of water, the experiments were performed using only three nozzles in the spray rings because the other nozzles would not have any effect in the collecting of water. The water flow rate varied as shown in Table 2 and the gauge pressure was kept in 0,25 $\mathrm{MPa}$.
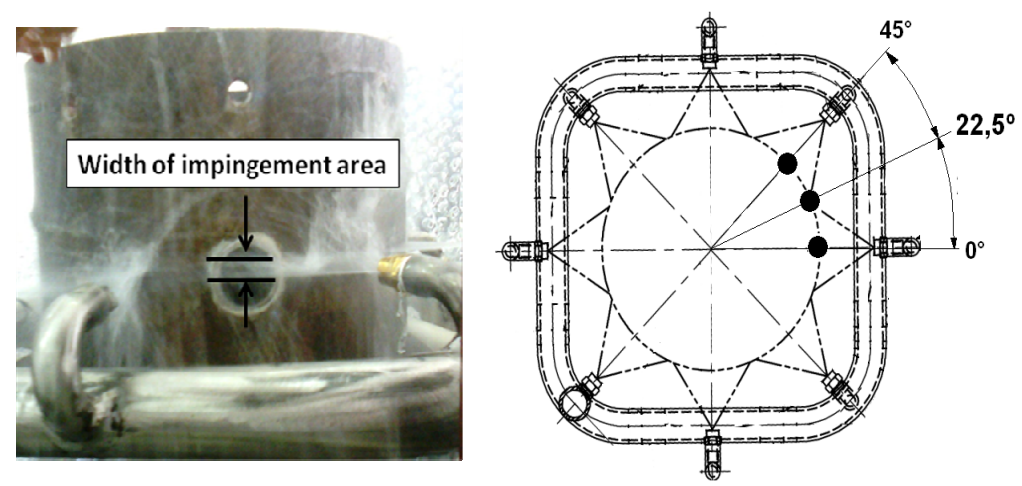

Figure 2. Scheme of Zone 0 positioning

Table 2. Water flow rate variation in zone 0

\begin{tabular}{|c|c|c|c|c|c|c|}
\hline Number of experiment & 1 & 2 & 3 & 4 & 5 & 6 \\
\hline Experimental water flow rate $\left[1 . \mathrm{min}^{-1}\right]$ & 7,0 & 9,0 & 11,0 & 13,0 & 16,0 & 18,0 \\
\hline Corresponding water flow rate $\left[1 . \mathrm{min}^{-1}\right]$ & 47 & 60 & 73 & 87 & 107 & 120 \\
\hline
\end{tabular}

Nozzles 1/4 GGA - 3.9 (Spraying Systems) were used for zones A, B and C. This kind of nozzle has a full cone spray with a circular impingement area, as shown in Figure 4. Symmetries in both vertical and horizontal axis were assumed, and then the measurements were performed in one quarter of the water impingement area. The hole was placed at five different positions in the longitudinal direction and at three positions in the angular direction, as shown in Figure 4. The distance between the hole and the spray ring was $115 \mathrm{~mm}$, which is the same distance between the billet and the spray ring in the plant. These measurements were performed with four nozzles in the spray ring. The water flow rate varied from $2,9 \mathrm{I} \cdot \mathrm{min}^{-1}$ up to $5,8 \mathrm{I} \cdot \mathrm{min}^{-1}$ and the gauge pressure was kept in 0,29 MPa, as shown in Table 3.

\section{RESULTS AND DISCUSSION}

\subsection{Water Distribution}

Since the local water flux density was measured for different water flow rates, an index of water flux density was defined, according to equation 12 , to enable the analysis of water distribution for different situations.

$$
I_{W D}=\frac{\left(\frac{W D_{\text {exp }}}{W_{\text {ring }}}\right)_{i}}{n_{i}}
$$

where $I_{W D}$ is the index of water flux density $\left[\mathrm{m}^{-2}\right], W D_{\exp }$ is the experimental water flux density $\left[1 . \mathrm{s}^{-1} . \mathrm{m}^{-2}\right], \quad W_{\text {ring }}$ is the water flow rate of the spray ring $\left[\mathrm{l} . \mathrm{s}^{-1}\right]$ and $n_{i}$ is the number of experiments. Thus, the local water flux density was calculated multiplying the index of water flux density by the water flow rate of each cooling zone. 
Figure 3 shows the index of water flux density of zone 0 for the eight nozzle condition (spray rings 1 and 2) and four nozzle condition (spray ring 3 ). The results for the eight nozzle condition at the angle $22,5^{\circ}$ were not computed due to experimental issues.

The index of water flux density has a small variation in the angular direction for the eight nozzle condition making the water distribution almost uniform for the first two spray rings. The index of water flux density varies considerably for the four nozzle condition. This difference is due to the lack of a nozzle at the angle of $0^{\circ}$ in the third spray ring.

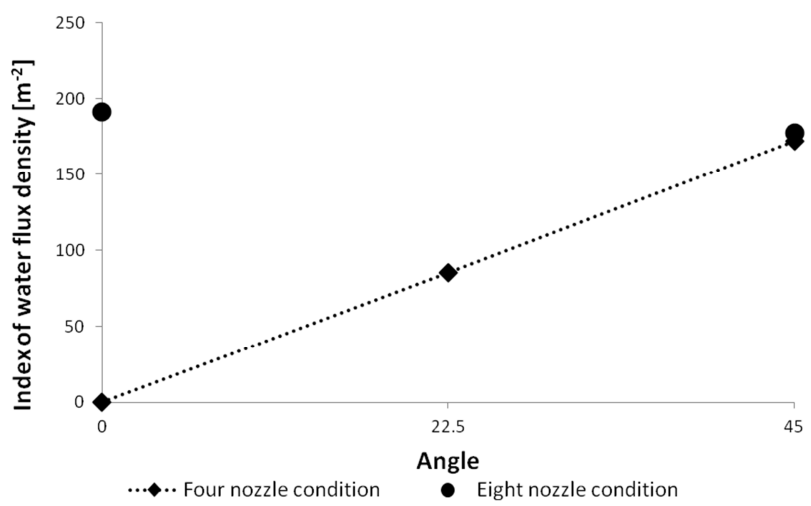

Figure 3. Index of water flux density of zone 0

Figure 4 shows the index of water flux density inside the water impingement area of the spray rings of the zones $\mathrm{A}, \mathrm{B}$ and $\mathrm{C}$.
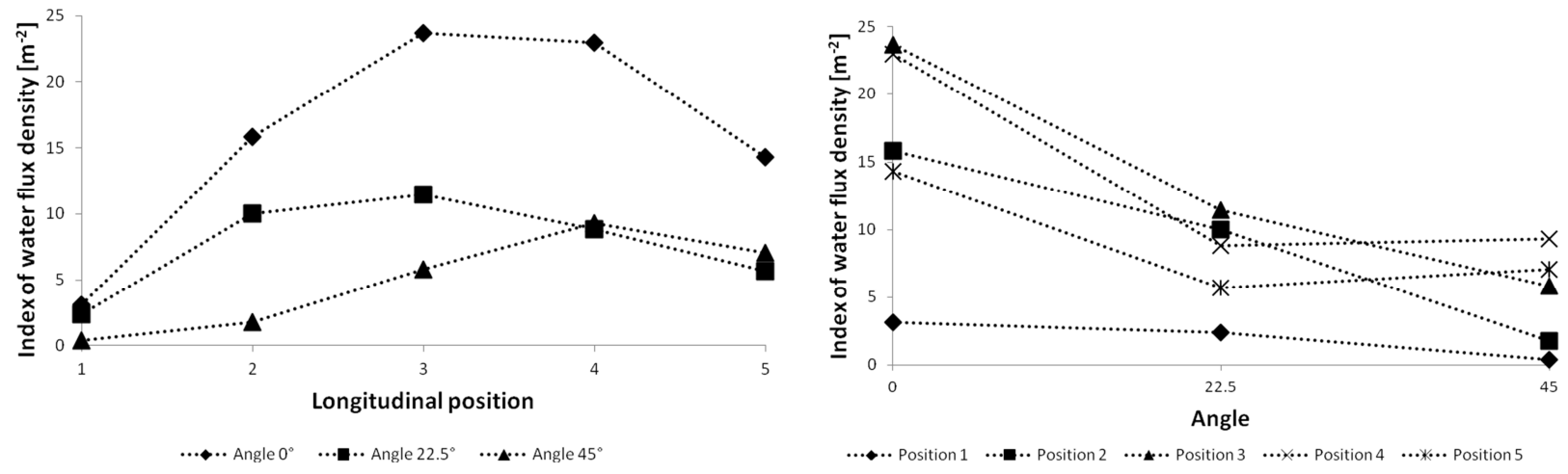

Figure 4. Index of water density for zones A, B and C

The water distribution is not uniform in both longitudinal and angular directions. In the longitudinal direction for any angular position, the index of water flux density increases from the outer to the inner positions. It reaches its maximum value at the intermediate position and it decreases as the position gets closer to the center of the water impingement area. This profile agrees with that obtained elsewhere [26] and confirms that the full cone nozzles do not have an even water spray. The index of water flux density varies considerably in the angular direction also because of the curvature of the tube. The higher the angle, the smaller the normal area of the collecting hole 'viewed' by the nozzle and then less water would impinge and be collected.

Besides the non-uniformity of the water spray of the nozzles, the water sprays do not cover all the surface of the strand and there are several dry areas where the cooling is due to natural convection and radiation mainly 
Figure 5 shows the water flux density along the cooling zones considering both uniform water distribution, which uses the average water flux density [27], and nonuniform water distribution, which considers the experimental water flux density. Although the total amount of water is the same, the water distribution profiles are totally different.

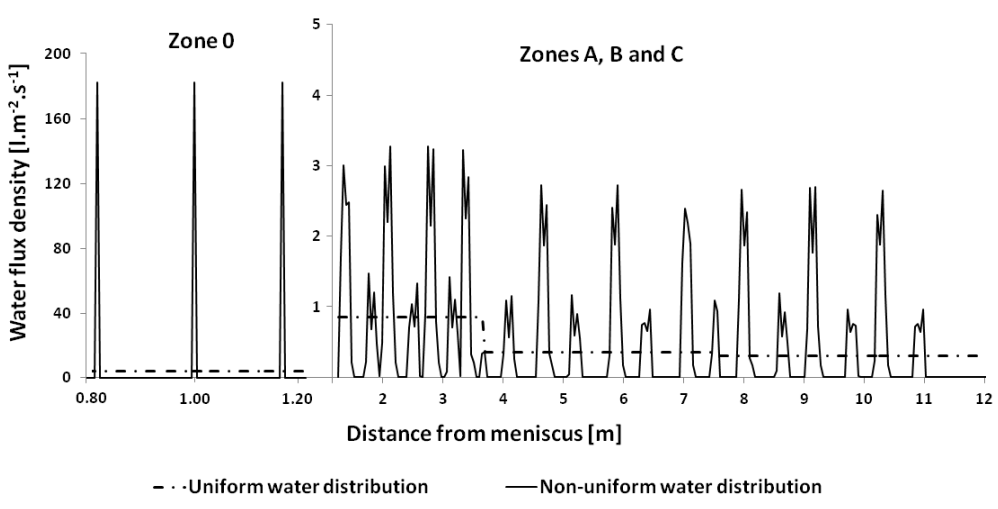

Figure 5. Water density distribution

\subsection{Mathematical model}

The results of water distribution were applied on the mathematical model of heat transfer and solidification of the round billets. The casting conditions during four temperature measurements are shown in Table 4.

Table 4. Operational parameters during the temperature measurements

\begin{tabular}{|c|c|c|c|c|}
\hline Parameter & $\# 1$ & \#2 & \#3 & $\# 4$ \\
\hline Steel grade & 4133 & 4133 & ST52 & E355 \\
\hline Diameter of the round billet [mm] & 230 & 230 & 180 & 180 \\
\hline Casting speed [m/min] & 0,79 & 1,01 & 1,73 & 2,03 \\
\hline Tundish temperature $\left[{ }^{\circ} \mathrm{C}\right]$ & 1557 & 1514 & 1537 & 1532 \\
\hline Temperature at $\mathrm{z}=1,30 \mathrm{~m}\left[{ }^{\circ} \mathrm{C}\right]$ & 1236 & 1228 & 1186 & 1217 \\
\hline Temperature at $\mathrm{z}=4,07 \mathrm{~m}\left[{ }^{\circ} \mathrm{C}\right]$ & 1122 & 1138 & 1187 & 1189 \\
\hline Temperature at $\mathrm{z}=7,65 \mathrm{~m}\left[{ }^{\circ} \mathrm{C}\right]$ & - & 1063 & 1133 & 1136 \\
\hline Temperature at $\mathrm{z}=11,50 \mathrm{~m}\left[{ }^{\circ} \mathrm{C}\right]$ & 1013 & 1006 & 1108 & 1139 \\
\hline Water flow rate in mold [l/min] & 1948 & 1950 & 1936 & 1934 \\
\hline Water flow rate in zone $0[\mathrm{l} / \mathrm{min}]$ & 39 & 50 & 101 & 118 \\
\hline Water flow rate in zone $\mathrm{A}$ [l/min] & 40 & 50 & 84 & 98 \\
\hline Water flow rate in zone $B$ [I/min] & 39 & 50 & 51 & 60 \\
\hline Water flow rate in zone $\mathrm{C}[\mathrm{l} / \mathrm{min}]$ & 23 & 30 & 51 & 60 \\
\hline
\end{tabular}

Figure 6 shows the superficial temperature profiles at the angles $0^{\circ}$ and $45^{\circ}$ and the shell thickness obtained by the mathematical model after the calibration. A good agreement between the measured and the calculated values of temperature was obtained. The maximum difference found was $28^{\circ} \mathrm{C}$ for the angle $0^{\circ}$ and the second position of measurement. The solidification profile is similar to those found in the literature [14,15]. The differences of temperature in the angular direction are observed from the third spray ring of zone 0 . The temperature drop after the third spray ring at the angle $45^{\circ}$ is around $17^{\circ} \mathrm{C}$, whereas at the angle $0^{\circ}$ is almost $65^{\circ} \mathrm{C}$, as shown in the zoomed area of Figure 6. 


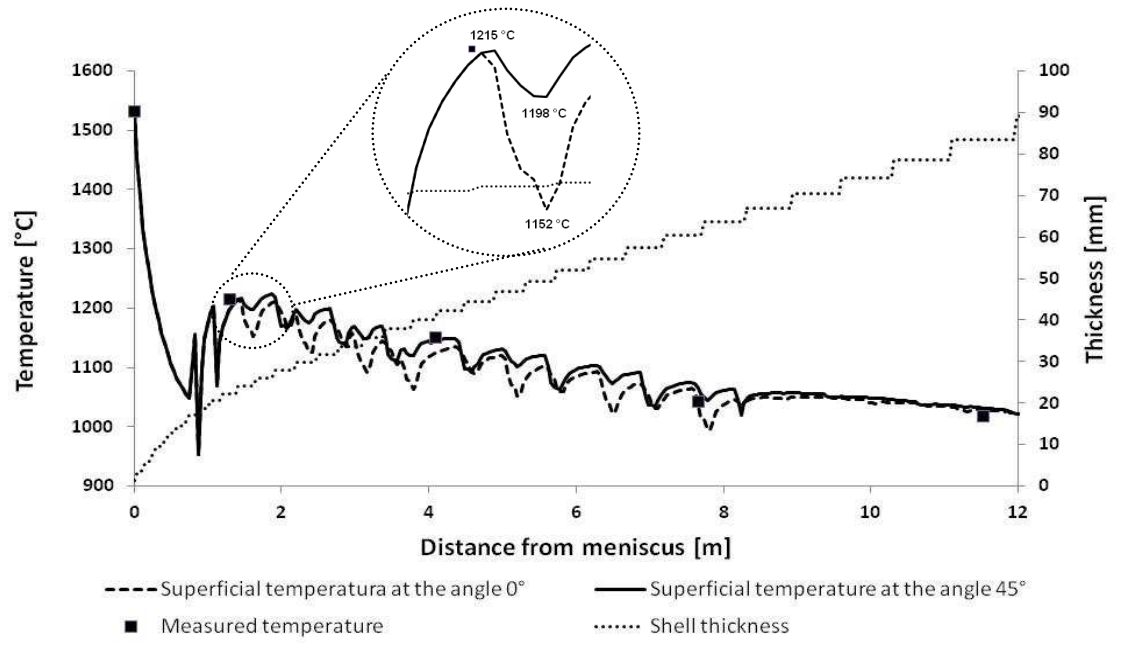

Figure 6. Results of superficial temperature and shell thickness variations

The mathematical model was used to evaluate the effects of the non-uniformity of water flux density. Figure 7 shows the profile of the global HTC in the longitudinal direction. The non-uniformity of water density has an important effect on the global HTC, since the local water flux density is the main factor that affects the heat transfer by convection ${ }^{17}$. The highest variation of the global HTC occurs in the cooling zone 0 . The peak values are approximately $6000 \mathrm{~W} \cdot \mathrm{m}^{-2} \mathrm{~K}^{-1}$, whereas the lowest values area approximately $220 \mathrm{~W} \cdot \mathrm{m}^{-2} \mathrm{~K}^{-1}$. If a uniform water density was considered the global HTC would be approximately $500 \mathrm{~W} \cdot \mathrm{m}^{-2} \mathrm{~K}^{-1}$ along the whole zone. In the zones $\mathrm{A}, \mathrm{B}$ and $\mathrm{C}$, the global HTC varies from $200 \mathrm{~W} \cdot \mathrm{m}^{-2} \mathrm{~K}^{-1}$, at the dry areas, up to 500 W. $\mathrm{m}^{-2} \mathrm{~K}^{-1}$, at the wet areas. The global HTC would be approximately $300 \mathrm{~W} \cdot \mathrm{m}^{-2} \mathrm{~K}^{-1}$ for a uniform water distribution.

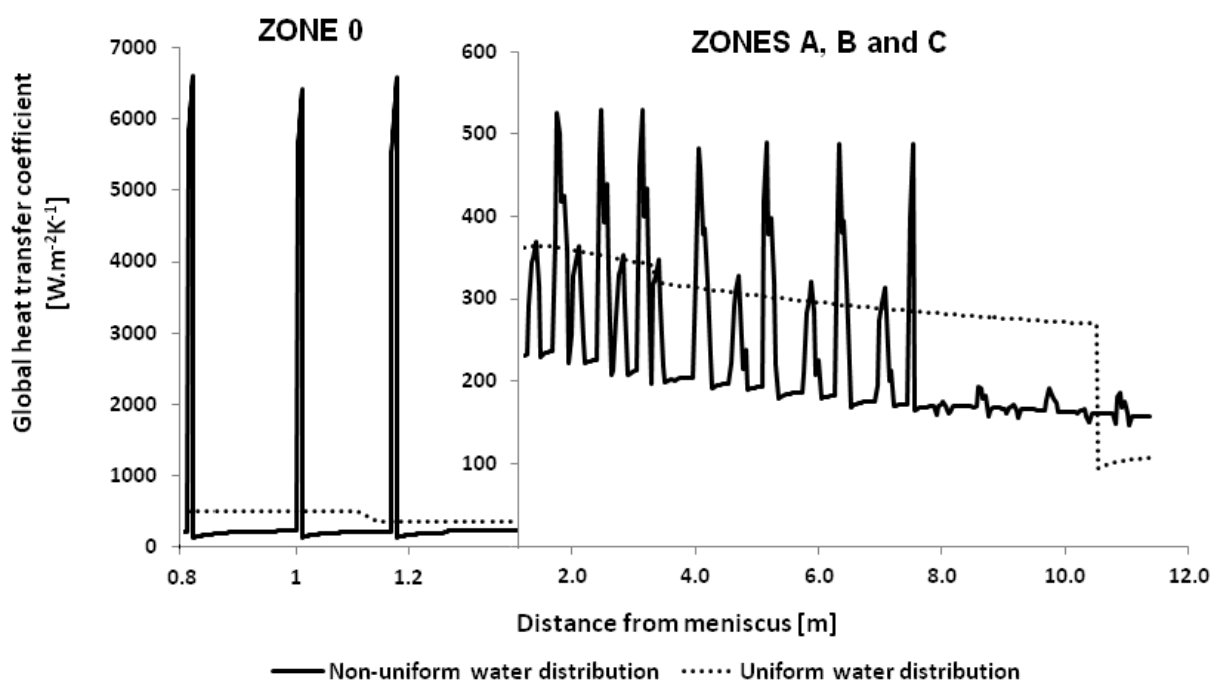

Figure 7. Global HTC variation in the longitudinal direction

Figure 8 shows the temperature profiles in the longitudinal and angular directions in zone 0 . In the longitudinal direction, the temperature varies intensely right after the three spray rings, with temperature drops larger than $230^{\circ} \mathrm{C}$. In the angular direction, the temperature distribution is uniform at the first and second spray rings, but, at the third spray ring, the temperature variation is approximately $232^{\circ} \mathrm{C}$. The temperature 
variation in both longitudinal and angular directions is much higher than the acceptable limit of $100^{\circ} \mathrm{C}[28]$.
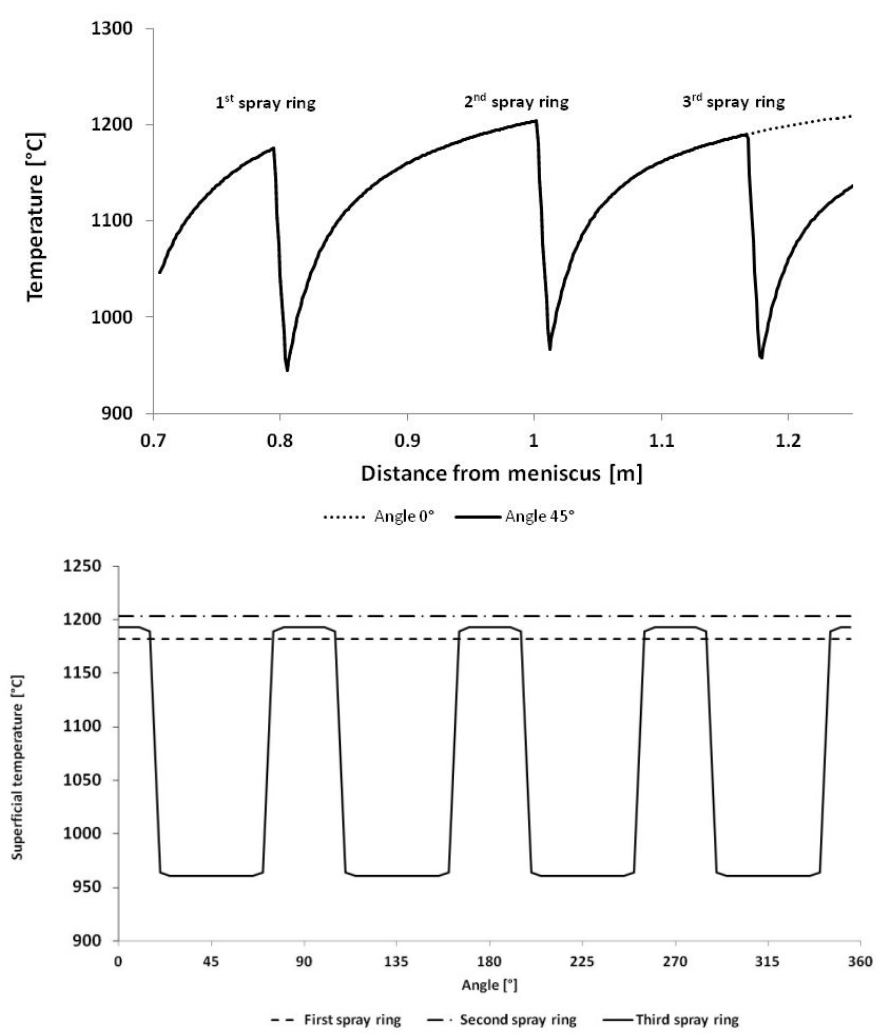

Figure 8. Superficial temperature variation in the zone 0

In order to reduce the heat transfer and superficial temperature non-uniformity, the change of the water flux density profile was simulated inputting the water distribution of the full cone nozzles instead of the flat jet nozzles in zone 0 . Figure 9 shows the superficial temperature as a function of the water flux density of each nozzle type. The current flat jet nozzles generate an overcooling followed by a reheating at the ring positions. Under these conditions, the billet could be overcooled or reheated very intensely.

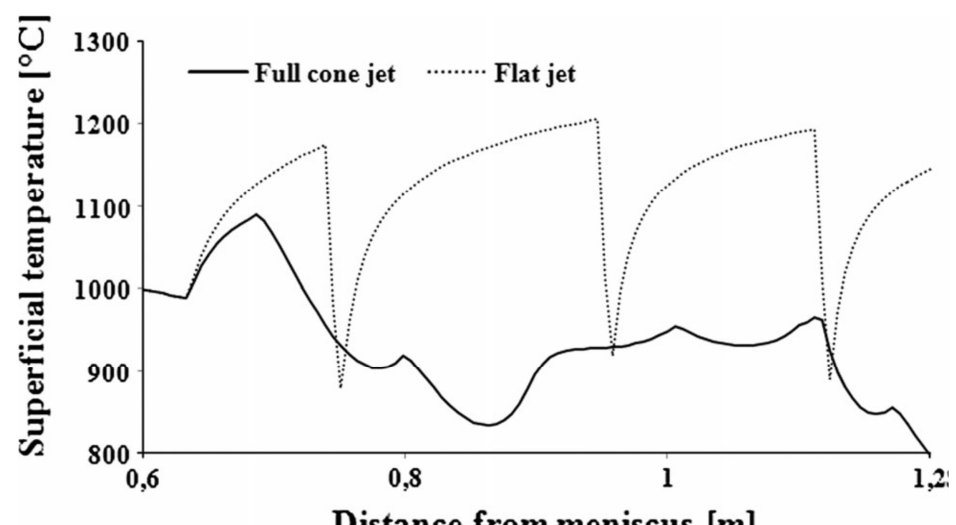

Figure 9. Superficial temperature variation as a function of the nozzle type

Under these conditions, the billet could be overcooled or reheated very intensely and in different ways at the same transversal section or in following slices as it passes through the zones, especially in zone 0 . 
The non-uniform cooling causes severe superficial thermal gradients which can generate process deviations as expansion of billet surface, tensile stresses and strains at solidification front, compressive stresses on the surface and tensions on billet surface. These process deviations could result in longitudinal internal cracks, midradial cracks, and longitudinal depressions with subsurface longitudinal facial cracks [12].

\section{CONCLUSION}

A mathematical model of the heat transfer and solidification for a continuous casting of round billet was developed and calibrated with superficial temperature measurements in a industrial plant. Experimental measurements of water distribution in the secondary cooling zone were performed using flat jet and full cone jet nozzles. An index of water flux density that relates the water distribution with the total amount of water was defined and applied on the mathematical model. The experiments showed that the water distribution is not uniform in both angular and longitudinal directions for both types of nozzles. The amount of water at the positions aligned with the nozzle is bigger than at the positions aligned with the intersection of two water impingement areas. This difference is due to the unevenness of the nozzle spray and the effect of the curvature of the tube, which reduces the area of water impingement. There are several dry areas along the strand, especially in the cooling zone 0 where the water density is concentrated in very small areas. The mathematical model was used to investigate the effect of the non-uniformity of water distribution on heat transfer coefficients, billet temperatures and shell thickness.

The non-uniformity of the water distribution causes important variations in the heat transfer coefficients and superficial temperatures in both longitudinal and angular directions. These variations are more intense in cooling zone 0 where the water distribution is more uneven. This approach was used to simulate the modification of water flux density in zone 0 which was simulated and to analyze the effects of the water flux density on cooling of the strand. This non-uniform water distribution approach is a useful tool to enlarge the comprehension about the thermal behavior of the steel along the secondary cooling in the continuous casting of round billets and to optimize the operational parameters to improve the quality of the as-cast product.

\section{REFERENCES}

1 A.S. Sabau, "Measurement of heat flux at metal/mould interface during casting solidification", International Journal of Cast Metals Research, Vol. 19, No. 3, 2006, pp. 188-194.

2 Y. Hebi, Y. Man, F. Dacheng, "3-D inverse problem continuous model for thermal behavior of mould process based on the temperature measurements in plant trial" ISIJ International, Vol. 46, No. 4, 2006, pp. 539-545.

3 B. Thomas, "Modeling of continuous casting of steel - past, present and future", Metallurgical and Materials Transactions B, Vol. 33B, December 2002, pp. 795-812.

4 J. Lait, J. Brimacombe, F. Weinberg : Ironmaking and Steelmaking, 2(1974), 90.

5 J. Brimacombe, "Design of continuous casting machines based o heat-flow analysis: state-of-the-art review", Canadian Metallurgical Quartely, Vol. 15, No. 2, 1976, pp. 1728.

6 B. Petrus et al. "Real-time, model-based spray-cooling control system for steel continuous casting", Metallurgical and Materials Transactions B, Vol. 42B, February 2011, pp. 87-103. 
7 J. Ma, Z. Xie,G. Jia, "Applying of real-time heat transfer and solidification model on the dynamic control system of billet continuous casting. ISIJ International, Vol. 48, No. 12, 2008, pp. 1722-1727.

8 R. Mahapatra, J. Brimacombe, I. Samarasekera, N. Walker, E. Paterson, J.Young: Metallurgical Transactions B, 22B(1991), 861.

9 H. Gilles: Making, Shaping and Treating of Steel, Vol. 18, AISE Steel Foundation, Pittsburgh (2003).

10 S. Summerfield, D. Fraser, "A new heat transfer correlation for impinging zone heat transfer on a hot steel plate", Canadian Metallurgical Quarterly, Vol. 45, 2006, pp. 69.

11 I. Samarasekera, C. Chow: Making, Shaping and Treating of Steel, Vol. 17, AISE Steel Foundation, Pittsburgh (2003).

12 V. D. Tutarova, D.Safonov, N. Shapovalov, "Density distribution of spray from flat spray nozzles in the secondary-cooling zone of a continuous caster", Metallurgist, Vol. 56, 2012.

13 J. Brimacombe, I. Samarasekera, J. Lait. Continuous Casting, Vol. 2, Bookcrafters, Chelsea (1984)

14 K. Zheng, B. Petrus, B. Thomas, J. Bentsman: Proc. of AISTech Steelmaking Conference, AIST, (2007)

15 Y. Meng, B. Thomas, "Heat transfer and solidification model of continuous slab casting: CON1D", Metallurgical and Materials Transactions B, Vol. 34B, 2003, pp. 685 .

16 H. Wang, G. Li, Y. Lei, Y. Zhao, Q. Dai, J. Wang, "Mathematical heat transfer model research for the improvement of continuous casting temperature", ISIJ International, Vol. 45, 2005, pp. 1291.

17 S.V. Patankar: Numerical heat transfer and fluid flow, Taylor\&Francis United States of America, (1980), 197p.

18 M. Flemings: Metallurgical Transactions B, Vol.5, 1974, pp. 2121.

19 J. Brimacombe: Canadian Metallurgical Quartely, Vol.15,1976, pp.17.

20 J. Brimacombe, L. Baptista Warrendale: Iron and Steel Society, Vol. 1, 1984, pp. 109.

21 X. Huang, B. Thomas, F. Najjar: Metallurgical Transactions B, Vol. 23B, 1992,pp. 339.

22 A. Howe: Ironmaking and Steelmaking, Vol. 15, 1988, pp.134.

23 H. Wang, G. Li, Y. Lei, Y. Zhao, Q. DAI, J. WANG: ISIJ International, Vol 45, 2005, pp.1291.

24 J. Brimacombe, F. Weinberg, E. Hawbolt: Continuous Casting. Heat Flow, Solidification and Crack Formation, Vol. 2, 1984, pp. 215.

25 P, Ingerslev, H. Henein: Iron and Steelmaker, .Vol. 24, 1997, pp.75

26 H. Muller, R. Jeschar: Archiv Eisenhuttenwesen, Vol. 44, 1973, pp. 589.

27 S. Hibbins: Characterization of heat transfer in the secondary cooling of a continuous slab, Department of Metallurgical Engineering, University of British Columbia, Vancouver, 1982, pp. 201.

28 J. Brimacombe, P. Agarwal, S. Hibbins, B. Prabhaker, L. Baptista: Continuous Casting. Heat Flow, Solidification and Crack Formation, Vol. 2, 1984, pp.109 